\title{
Communicating Identity in the Workplace and Affinity Group Spaces
}

\author{
Megan M. Lambertz-Berndt ${ }^{1}$ \\ ${ }^{1}$ California Polytechnic State University, USA \\ Correspondence: Megan M. Lambertz-Berndt, California Polytechnic State University, USA.
}

Received: September 12, 2016

Accepted: October 7, 2016 Online Published: October 29, 2016

doi:10.11114/smc.v4i2.1952

URL: http://dx.doi.org/10.11114/smc.v4i2.1952

\begin{abstract}
The following paper examined affinity group creation and purpose through an identity management lens by addressing the utility of an affinity group for those currently involved in homogeneous racial and nonracial groups as well as larger organizational diversity sessions. A thematic analysis revealed affinity group perceptions including several subthemes (logistics, helpful, harmful, more heterogeneity, and exclusion of identity). Organizational diversity sessions at large revealed similar subthemes (legitimizing identity, lack of safe spaces, intersectionality, and surface level discussions). Understanding how employees view organizational diversity efforts better equip organizations to enact specific diversity strategies that move beyond the mere rhetoric of diversity.
\end{abstract}

Keywords: affinity groups, identity, diversity, intersectionality, thematic analysis

\section{Introduction}

Diversity remains a common goal among businesses, organizations, and educational institutions. The United States Department of Labor (2014, October 13) predicts by 2050, one in every four Americans will identify as a racial minority such as Hispanic, Black, or Asian American Pacific Islander (AAPI). Changing demographics require that organizations recognize the need to increase diversity and how to create and foster an inclusive climate. Starbucks president, Howard Schultz, recently implemented a race conversations campaign, which empowered Starbucks employees to discuss events and issues surrounding race into the workplace dialogue. Although, well intended, the campaign quickly became controversial, and subsequently fizzled after critics (1) claimed employees lacked the experience to engage in such sensitive dialogue (Harlan \& Contrera, 2015, March 22) and (2) suggested Starbucks sought to capitalize on recent racial incidents (e.g. Ferguson) (Dean, 2015, March 22). Starbucks provided one of the first multi-million dollar campaigns to publicly integrate diversity into the workplace dialogue, however, "diversity rhetoric and initiatives do not necessarily lead to positive climates nor is the link between a positive climate and enhanced organizational effectiveness always a strong one" (Groggins \& Ryan, 2013, p. 265). Therefore, companies must move away from the surface level discourse concerning diversity and understand the implications of communicating a personal identity in the workplace. To do so, first one must examine why current diversity initiatives lack permanence.

Diversity initiatives often fail due to a myriad of reasons including equating the campaigns to affirmation action, and treating the initiative as a set of legal guidelines (Roberts, 2011). Affirmative action's historic roots come from the civil rights movement where disadvantaged groups benefitted from a preference during the hiring process, while diversity initiatives aim at changing organizational culture, including hidden biases within organizational practices (Stoney Brook University, 2015). U.S. organizational culture is rooted in white middle class blue collar bias and thus "it becomes clear that 'doing professional' is at least as much (if not more) about performing Whiteness" (Ashcraft \& Allen, 2003, p. 27) than performing one's job requirements. Ashcraft and Allen (2003) argue that five messages convey the lack of diversity in most organizational contexts: (a) race as separate and only applicable in certain circumstances; (b) race only involves cultural differences; (c) cultures are homogeneous; (d) racial discrimination results from individual biases and interpersonal misunderstandings; (e) white-collar standards constitute universal guidelines. The challenge of conceptualizing diversity within an organization results from a complex web of intersecting identities and disruptive nature of focusing on sensitive and emotionally charged issues such as race (Blitz \& Kohl, 2012). Using the five messages reflect an organization's inability to firmly conceptualize diversity and offer specific strategies to increase inclusion.

The decision of whether to share either one's social identity may depend on organizational culture, the cultural 
background of the employee, and the perception of the organization's willingness to accept diversity. Complex identities require employees to constantly negotiate what identity aspects to reveal or conceal (Gulati \& Carbado, 2000). Business enthusiast magazines such as Forbes offer quick and easy tips to control revealing identity in the workplace including "adopt a new mindset, invest yourself continuously, and adjust your vision" (para. 6), yet the decision of whether or not to discuss identity becomes much more complex. Individuals must negotiate between the visible and invisible identities. Visible social identities, such as one's skin color or gender, may be easy for organizational members to identify whereas invisible social identities such as one's sexual identity or, deep seated values and attitudes are less easy to detect and manage within the workplace (Clair, Beatty, \& Maclean, 2005).

Organizational communication scholars rarely include racial issues in research, yet there remains a need to examine whiteness while addressing race as a theoretical issue (Ashcraft \& Allen, 2003). In an effort to continue with such standards as identified by Ashcraft and Allen (2003), this paper addresses race in the workplace from a communication lens. Organizations continue to employ a wide range of diversity initiatives intended to help promote inclusiveness in the workplace, yet one tactic few organizations employ to enhance diversity involves the creation and inclusion of both homogeneous and heterogeneous affinity groups. The following uses identity management theory to examine affinity group creation and purpose. The results and implications of the following study address the utility of an affinity group for those currently involved in homogeneous racial and nonracial groups.

\section{Literature Review}

Affinity groups, consisting of individuals or employees sharing a common characteristic, trait, or interest, discuss issues of shared identity (Segal, 2013) and provide emotional support or potential resources for employees (Douglas, 2008). Affinity groups include homogeneous groups, comprising of individuals sharing the same identity characteristic such as an African American affinity group, where all members must identify as African American. Heterogeneous groups include individuals with the same identity characteristic in addition to allies. Allies include supporters for equal rights, and gender or racial equality that do not share the unique characteristic of the group.

Affinity groups remain voluntary, yet organizations differ on inclusivity. Some organizational affinity groups include all employees, even employees not sharing the primary characteristic (Fair Employment Practices Guidelines, 2006). Johns Hopkins University (2015) offers affinity groups to all who support or identify with the common characteristic. For instance, attending the LGBTQ groups does not require identification as LGBTQ, with all alumni, current students, and friends of the university welcome to interact. The inclusion of all individuals is not ubiquitous. Several non-profit educational organizations offer affinity groups to new employees; However, attendees must identify with the characteristics of the group. For instance, a White person could not join the African American affinity group since he or she does not racially identify with the group. Meenai (2003) concludes that "groups formed on the basis of affinity offered their members much greater support, than groups pulled together that did not share similar bonds" (p. 29).

While some businesses and organizations either take on a homogeneous or heterogeneous approach to affinity group formation, other organizations prohibit certain types of affinity groups. General Motors (GM) excluded religious affinity groups due to the organization's affinity group guidelines stating groups cannot "promote or advocate particular religious or political positions" (McGlothlen, 2006, para. 24), which led to several discrimination law suits. When organization's offer affinity groups to some and not others, legal challenges most likely arise (McGlothlen, 2006). Few organizations offer both types of group formations due to financial limitations and a lack of organizational resources (e.g. office and room space). Affinity groups operate under the assumption that individuals share an affinity when entering a group space, yet such affinities differ depending on intersectionality.

Although inclusiveness remains contingent on the organization and the decision on whether to include allies, inclusiveness resides in the perceptions of the group members. Due to a variance in privilege, or a perception of social advantage, some group members become stigmatized. Privilege denotes a benefit or social position given to some and not others; often privilege becomes divided into racial and nonracial privilege. One racial privilege in the United States, white privilege, refers to the advantages received "simply by virtue of one's appearance and, to a lesser degree, the privilege lighter skinned people of color garner as compared to darker members of the same or different non-White racial groups" (Singleton \& Linton, 2006, p. 183). For instance, within an African American affinity group, a biracial individual might be perceived as more privileged compared to monoracial African Americans (Sanchez \& Bonam, 2009).

One form of nonracial privilege is heterosexual privilege. Heterosexual privilege describes the assumption that heterosexuality operates as the norm, and living without having to think or confront topics such as discussing one's relationship, fear of traveling to less accepting areas, and not questioning one's normality, to name a few (University of Duluth Minnesota, 2015). A bisexual individual within an LGBTQ affinity group may be perceived as more privileged due to social stigma's such as the ability to "choose" a heterosexual relationship. 
The varying levels of privilege within perceived homogeneous groups reflect assumptions and attributes still containing heterogeneity. As indicated by Ashcraft and Allen (2003), assuming homogeneity for one particular culture hinders diversity efforts. Differences among perceived levels of privilege may create exclusivity within groups or a lack of socially appropriate cultural understanding. After studying surface and deep level diversity within workgroups, Mohammad and Angell (2004) found that even the slightest distinctions in one's demographic characteristics may result in feelings of hostility or animosity. Affinity groups operate under the assumption of shared identity. Therefore, discussing differences can cause disruption. Some organizations address such elements of intersectionality by including multiple racial and nonracial identity types such African American, Biracial, and People of Color, however offering multiple groups depends on organizational resources.

Additionally, affinity groups serve a variety of functions outside of the workplace including bullying prevention (Nurenburg, 2014), as a support group (Goldberg, 1990), educational development (Linchevski \& Kutscher, 1998; Sheppard, \& Kanevsky, 1999) and in-group-out-group status (Biernat, Vescio, \& Billings, 1999). Each context utilizes affinity groups as a way to promote self-identification or create a support unit for persons sharing similar traits or experiences. A promising exploration involves using identity management theory (IMT) to assess how employees manage and negotiate cultural identity within the workplace, and how affinity groups facilitate and hinder the process. The following explores the two primary goals of an affinity group, an examination of IMT to better understand the relational and cultural identities an employee must manage within both racial and nonracial affinity groups, as well as the methods. The next section provides a better understanding of why individuals join affinity groups.

\subsection{Affinity Group Purpose}

Affinity group purpose falls into one of two categories: emotional and instrumental. The emotional purpose of an affinity group allows for an expressive outlet on highly sensitive topics. For instance, Parsons and Ridley (2012) claim "the relationships students gain through race-based affinity groups enable them to feel less alone with their emotions and help them build a stronger sense of self" (p. 40). Affinity groups provide participants the opportunity to discuss emotional topics related to sharing identity characteristics such as race, sexual orientation, or religious beliefs, not readily available during classroom or work related discussions (Michael \& Conger, 2012). Gathering persons sharing similar experiences and challenges, provides an important feeling of unity.

Unifying those within an affinity group results from the sharing of discrimination or separation from others within the workplace. Camins (2014) argues that the workplace, where multiple identities operate, experience an empathy gap. Individuals may try to empathize with each other, but the challenge exists for the "empowered to visualize what it is like to be disempowered, especially without social pressure to do so" (Camins, 2014, para. 6). Singleton and Linton (2006) argue that the empowered can ignore or walk away from conversations about race, while the disempowered must confront racial issues on a daily basis. Thus, empathizing requires more than merely attempting to place oneself in another's shoes. Instead, relational empathy in an intercultural interaction requires a "dynamic process that necessitates taking steps to synthesize conflicting perspectives" (Kurylo, 2013, p. 337), which could cause difficulty when a perspective differs from one's own. For instance, a White employee may find difficulty empathizing with a Black employee on racial profiling due to a lack of experience and a discomfort in sharing the identity characteristic of those committing the discrimination. Although sympathizing with an individual may lend emotional support, the potential for others to empathize creates a stronger connection. Companies such as Hewitt Packard, Microsoft, and Dell acknowledge the emotional purpose of affinity groups in retaining employees, and highlight the instrumental goals by sharing information, and increasing awareness of organizational policies and procedures (Lengnick-Hill, 2007). Consequently, affinity groups within companies serve more than one function for employees.

Instrumental affinity groups move beyond emotional outlets to consider the actions needed to accomplish specific goals. Van Aken, Monetta, and Sink (1994) surveyed white collar affinity groups which "promote the sharing of information and knowledge across organizational functions; enhance employees' problem-solving skills; encourage systems thinking and an appreciation for the overall organization; help employees identify and address education and training needs; and advance horizontal and vertical communication" (p. 53). Moving the discourse of affinity groups to action steps enhances the organizational experience by improving policies or enhancing communication amongst employees. McLean-Conner (2008) claim that "successful affinity groups develop a business plan stating their goals and outlining initiatives to achieve the goals" (para. 7). When individuals discuss issues pertaining to changing the organizational structure, more tangible results are likely. Examples of tangible results include an increased social awareness concerning the challenges of one's identity characteristic.

Affinity groups increase social awareness. The International Leadership Association (ILA) created affinity groups for the purpose of providing networking tools, and to spread awareness about women in leadership positions. Additionally, college racial affinity groups remain instrumental in providing minority scholarship information, specifically to certain 
socially disadvantaged groups. Creating a space to share resources supports student's navigation through institutional requirements (Hallett, 2013). Without the racial affinity groups, some student populations may lack the necessary information to continue with a degree program. Hallett (2010) conducted an ethnography on peer support for undocumented Latino college students finding that due to the restraints of being far away from family and "the campus context limited resources, Latino/a students relied on peers to gain access to information necessary to remain in school" (p. 110). The peer groups helped the undocumented students navigate the institution requirements, while learning from those with experience successfully navigating the institutional process. Arguably, without the racial affinity groups, the Latino students in Hallett's study may have lacked the necessary information and confidence to continue with the degree program.

Regardless of the affinity group type, employees need a place for social sharing and support for identity, while simultaneously desire a discussion of issues pertaining to the workplace. For instance, an employee may vent about a threat to one's identity, as well as collaborate on how to address the issue in the workplace to avoid such instances. Both approaches deal with emotional issues and collaboration, by creating an attempt to legitimatize the identity, while avoidance simply conceals a potentially divisive or difficult issue. Racial and nonracial homogeneous affinity groups possess the ability to provide a supportive climate in an organizational context, however managing multiple identities within such spaces remain challenging.

\subsection{Identity Management Theory}

Different cultural groups possess varying expectations concerning the social appropriateness of communication behaviors (Imahori \& Cupach, 2005). For example, within the African American community, many group members understand the environmental pressure of completing an education. Noguera (2003) ascertains that African American students "can be unfairly victimized by the labeling and sorting processes that occur within school in addition to being harmed by the attitudes and behavior they adopt in reaction to these processes" (p. 442). Such environmental factors play a role in the social discourse within the African American community and one must understand the developed perceptions when engaging in dialogue within an affinity group. Essentially, inequity within the field of education remains an unwritten perception adopted by many African Americans with group members understanding these perceptions in order to communicate effectively within the group setting.

Identity management theory (IMT) seeks to explain cultural identities over time based on interpersonal relationships (Imahori \& Cupach, 2005). IMT applies to affinity group communication due to the underlying theoretical assumption that cultural identities result in communication difficulties (Oetzel \& Ting-Toomey, 2005), understanding cultural norms, and justifying one's identity via affinity groups. Reoccurring causes of intercultural communication difficulties include "defensiveness, different world views, different values and beliefs, prejudices, different languages, different ways of using and interpreting non-verbal codes, different ways of constructing messages, unequal power, and the failure to allow for individual cultural differences within a group" (Singh \& Rampersad, 2010, p. 1405). Understanding the cultural norms equips affinity group attendees with the requisite knowledge needed to fully comprehend the complexities of a culture. For instance, a young lesbian raised in an accepting community must understand the circumstance of many others, especially older members of the LGBTQ community who have faced numerous accounts of discrimination. Finally, one must justify one's affinity within a group space, rather than be a bystander due to the inherent goal of relating to those with shared experiences, which requires communicating those experiences to those within the group.

\subsection{Socially Acceptable Identities}

Due to the complexity of identity (e.g. social standing, gender, sexual orientation, race, ethnicity, etc.), a person must negotiate the most acceptable identity within the affinity group space. Individuals must communicate competently by negotiating socially acceptable identities within an interaction (Imahori \& Cupach, 2005). Socially acceptable identities might be difficult to determine due to unwritten social norms. For example, a member of an African American affinity group raised in a predominantly White neighborhood may lack exposure or awareness of the perceptions evolved from larger more homogeneous African American communities. The difference in upbringing might result in a group member's inability to relate to others within the group. Such an experience remains problematic due to the primary goal of an affinity group as a place for individuals with a shared identity characteristic to support one another. Individuals might not necessarily understand the appropriate social role associated with one's identity characteristic. Oetzel and Ting-Toomey (2005) claim that IMT presumes the formation of intercultural relationships assuming sufficient commonalities. The commonalities within an affinity group might be difficult to assume. The lack of knowledge may create difficulty, since affinity groups invoke the notion of individuals sharing commonality.

\subsection{Cultural Norms}

Cultural norms may be based in organizational practices that have historically discriminated against minorities, 
impacting the management of social identity. Shih, Young, and Bucher (2013) ascertain that workplace discrimination remains common, and difficult to combat due to the often subtle nature of the practice. Deitch, Barsky, Butz, Chan, Brief, and Bradley (2003) conducted a two-part study addressing everyday discrimination in the workplace and found that Blacks experienced subtler forms of race characterized by frequency of reported levels of mistreatment from fellow employees than the white counterparts. Deitch et al. (2003) cautiously defined everyday racism as self-identified mistreatment, yet other scholars (Guerin, 2005) offer a more concrete definition of everyday racism including comments regarding internal attributions which "allow reference to a negative outgroup, by allowing a conception of a problem beyond an abstract social/structural cause, by shifting the responsibility for change to another person, or by making it more difficult for someone to challenge your statements" (p. 47). Overt racist comments are becoming a rarity in the workplace, with everyday racism prominent and unacknowledged (Deitch et al., 2003; Guerin, 2005; Shih et. al., 2013). Unfortunately, non-white individuals find the need to work harder to overcome predetermined stereotypes developed based on racial identity (Parker, 2002).

By changing one's identity to accommodate for stereotypes, individuals face a difficult time displaying the authentic self in the workplace. For instance, an African American woman minimizing her passion during a meeting due to the common stereotype of the angry Black woman, limits her true identity. To assess identity negotiation, Parker (2002) used a thematic analysis of interviews with African American senior executives within a predominantly white organization, finding that some Black women employed a "self-surveillance in which they maintained a heightened awareness of their visibility as Black women" (p. 263). The senior employees continuously kept their racial identity at the forefront of each communicative act (Parker, 2002). Other Black women reported downplaying race as a potential constraint to their work when communicating with other employees (Parker, 2002). Both responses limit one's identity in the workplace by inhibiting ones authentic self.

Another example remains evident in nonracial communities such as those identifying as LGBTQ. Chrobot-Mason, Button, and DiClementi (2001) explored sexual identity management strategies in the workplace for lesbian and gay employees, revealing that the more inclusive the workplace climate, the more likely one reveals elements of his or her sexual identity. However, a large portion of responses suggested that maintaining a false identity may foster group interactions. Communicating identity in the workplace remains contingent on the workplace climate, whether supportive or stigmatized, and the strategies deemed socially acceptable by the individual (Croteau, Anderson, \& Vanderwal, 2008; Griffith \& Hebl, 2002).

\subsection{Justifying Identity}

Since employees of minority groups tend to endure increased mistreatment and constantly monitor inherent identities, change remains necessary. Deitch, Barsky, Butz, Chan, Brief, and Bradley (2003) found that "typical, one-time diversity training courses and nondiscrimination polices do little to alleviate the existence of everyday discrimination in the workplace" (p. 1317). Affinity groups may provide a space to discuss these common everyday discriminatory behaviors that remain prevalent in the workplace. In addition to understanding the differences within even the most homogenous groups creates communication difficulties, IMT provides an important lens into the perspectives concerning the justification of incorporating an affinity group within the workplace.

Businesses and organizations looking to incorporate affinity groups, must better understand the cultural norms of future employees and the justification of which type of affinity group would foster the most diversity within the workplace. Lambertz (2014) found negative perceptions of affinity groups due in part to whether individuals felt as though the identity characteristic became justified. For example, a white female employee from an educational non-profit organization stated of affinity groups, "To me, it seemed as though you were unwelcome or not as highly encouraged to attend groups that did not fit your characteristics." Based on the aforementioned statement, the employee felt as though heterogeneous affinity groups would have been more inclusive. Cole and Salimath (2013) conducted a study concerning identity management in diversity programs offered by organizations. They found "implementing diversity programs that are (perceived as) unjustified, results in negative attitudes and feelings directed toward the organization such as feelings of incompetence, dissatisfaction, and lack of commitment" (p. 159). The tactic to foster diversity in the workplace, became met with resistance, due a lack of understanding concerning cultural norms. In addition to understanding the preferred affinity group structure, individuals might find difficulty negotiating which elements of identity to share within the groups due to constant negotiations of which identity characteristic one should share in the workplace and appropriate social norms. Therefore, the following research questions were derived.

RQ1: Do affinity groups enhance diversity in the workplace?

RQ2: What will help to enhance diversity within the workplace at large? 


\section{Method}

The current research seeks to understand the way individuals communicate aspects of identity in the workplace. Participants consisted of employees from a large educational non-profit organization. The data obtained from the nonprofit organization included 220 responses from employees within a non-profit educational organization over the last two years, including the summer of 2015 and 2014. The educational non-profit organization holds a six-week training session each year to equip employees with the skills and resources required for success. During the 6-weeks, employees may voluntarily attend both racial and nonracial affinity groups outside of the designated work-day schedule. Often, the affinity group spaces occurred in the evenings after employees fulfilled daily training duties. At the end of the training period, employees completed a survey concerning experiences at the six-week training session, at six training locations over two years. Through a keyword search, the researcher assessed participant responses regarding identity within the workplace and affinity groups. Of the 220 responses, 62 addressed affinity groups directly, while 158 included a reflection of one's identity within the workplace in general. A majority of employees were female (69\%) and between the ages of 20-61 $(M=22)$. Employee racial identities were only reported for the 2015 data. Of the 140 employees from the 2015 training session, a majority identified as White $(51 \%)$. Other racial identities included Latino/a (18\%), African American (14\%), people of color (10\%), and Asian (7\%).

\section{Procedures and Measures}

The researcher conducted a thematic analysis of all open-ended survey items from the educational non-profit organization. Thematic analysis remains a useful analytic tool due to the volume of data obtained and the predetermined categories identified by the researcher (Attride-Stirling, 2001). Marshall and Rossman (1999) claim thematic analysis brings "order, structure and interpretation to the mass of data" (p. 150). The data included two years of an open-ended survey question inquiring about the employee's experiences at the six-week training session. During the training session, employees could attend various homogeneous racial and nonracial affinity groups. The open-ended survey question stated, "Please provide any other feedback you have regarding your response to the above questions." The prior questions included Likert type items (strongly agree to strongly disagree) addressing two statements including: "Affinity groups were a valuable space for me" and "I believe the diversity initiatives at sic (training session) enabled me to reflect on my identity, given my background." After a keyword search of identity, and affinity group within the survey responses, 220 met the inclusion criteria. The results highlight the function and utility of an affinity group as well as the impact on identity during the training session.

\section{Coding}

The author used a combination of Attride-Stirling (2001) and Marshall and Rossman's (1999) thematic phases including code the data, identify themes, search for alternative interpretations, and write the analysis. Attride-Stirling (2001) states that the coding framework can be based on pre-established criteria developed from research questions posed by the researcher. After reading through the 220 responses multiple times, the author organized the data into two larger categories including affinity group perception, and organizational identity. Two general categories emerged to address RQ1 including affinity group perceptions and identity management within the workplace. Responses grouped into "affinity group perception" contained the keywords words "affinity group," whereas identity management in the workplace contained words such as "identity" and "diversity." The two categories had specific boundaries and definitions to keep them distinct by using the specific keywords to separate the two types of responses. Responses including the mention of affinity groups contained content about the experiences when attending the affinity group meetings, whereas responses including the mention of identity or diversity contained content about experiences within larger organizational diversity sessions involving multiple racial and nonracial identities. Once the data had been organized into two general categories, the author extracted salient subthemes (Table 1).

The author read through 62 responses several times addressing affinity group perceptions. After reading through the data, the author identified salient subthemes. Initially, the researcher identified 7 subthemes, however grouped similar subthemes together. For example, many participants reported the time and location of the affinity group meetings as problematic for attendance. Initially, the researcher had both time and location as separate subthemes, yet condensed the theme to a larger subtheme titled logistics where time, location, and facilitation were then grouped together. Once the subthemes had been created, the author revisited the responses to refine them to be specific, yet general enough to include in one subtheme. Such a decision made the data more manageable for the researcher (Attride-Stirling, 2001). The general categories and their subthemes are reported below.

The coding framework consisted of multiple comparisons with another colleague to ensure the accuracy of the applied codes to each subtheme. Both coders had credentials in qualitative analysis. Both coders examined 25 responses for logistics, helpfulness, harmful, heterogeneity, and exclusion of identity. Subsequently, both coders did the same for 30 responses from the identity management category including the several subthemes: legitimizing one's identity, 
intersectionality, lack of safe-spaces, and surface-level discussion. Once the coders had each coded the 25 responses from each general category, reliability tests were conducted. To estimate variance and to measure agreement between raters, Cohen's Kapa was used. Results for affinity group perception revealed 1.00 logistics, 1.00 for helpfulness, 1.00 for harmfulness .89 heterogeneity and .93 for exclusion of identity. Results for identity management in the workplace revealed .93 legitimizing one's identity, .92 for intersectionality, 1.00 for lack of safe spaces, .and 1.00 for surface level discussions.

\section{Results}

RQ1: Are affinity groups considered a way to enhance diversity in the workplace?

\subsection{Affinity Group Perceptions}

62 responses addressed the utility of affinity groups directly. From responses, several sub-themes emerged: (a) logistics, including those concerned about the time and location of the affinity group spaces, (b) helpful, where groups served as a space to discuss topics not readily available in workplace dialogue, (c) harmful, which reminded employees of one's oppression or white guilt, (d) more heterogeneity, where either white participants sought to learn from blacks or individuals wanted to discuss more than one aspect of their identity, and (e) exclusion of identities including income level, women, Jewish religion, and LGBTQ.

\subsection{Logistics.}

Several employees reported problems with the timing, marketing, and facilitation of the affinity group meetings. For example, a Latino male employee stated

Affinity groups are not set up for SUCCESS! Timing and marketing are not there which makes affinity groups hard to become successful and opportunity to make significant positive change state wide! Reconsider different date and time along with location of places would increase attendance of these groups.

Many of the affinity groups took place late at night after the employees completed an eight-hour work-day. The affinity group spaces used the same facility as employee housing, yet the late hours seemed less than ideal for many employees looking to attend. Additionally, several responses addressed the lack of credentials of affinity group facilitators. An African American Male stated "some of the facilitators were not adequate and underprepared to handle some of the in depth conversations." The educational non-profit organization used for the study did not hire employees to lead affinity group meetings, rather facilitators were voluntary positions, with no guarantee of professional or educational expertise sought to discuss aspects of the racial or nonracial identity characteristic. The qualifications needed to serve as an affinity group facilitator merely included identifying with the racial or nonracial group characteristic and exhibiting an interest in issues pertaining to the group identity.

\subsection{Helpful}

Other employee responses highlighted the supportive environment provided in affinity group spaces. For instance, a Female Asian American employee stated "Loved this section and breaking off into affinity groups. It was great to learn about ourselves as well as what our students might identify with." From the above statement and responses alike, employees felt the affinity groups provided a space to discuss sensitive topics such as race, gender, sexuality, and religion not readily available during workplace dialogue. A white female employee stated "Talking about our racial identity and how that comes into the classroom was extremely helpful." Most responses failed to articulate what about the affinity group was helpful, indicating only that sharing the same space as those with common features created a positive experience for employees as well as relating to one's students after the training session was complete

\subsection{Harmful}

Although many responses highlighted the supportive nature of an affinity group, just as many responses addressed the harmful nature such as evoking white guilt or reminding employees of oppression. A white female stated "As a white person, I can't help to feel that we're so focused on exploring and knowing other identities that ours has been lost and undervalued throughout the process" or a white male stating

Like many students in this program, I felt that the sessions aimed more at making me feel guilty than at helping me value my identity. I am a white man from an upper-middle class background, but I have signed up to join the organization's effort.

The above responses demonstrate a lack of attention the organization provided to why one joined the movement and how one's white identity was only explored as a way to foster guilt. Joining the organization implies a shared goal of the overall mission, yet several white participants thought such an intention became lost when discussing the negative effects of one's white identity. Several leaders from the non-profit organization expressed that white affinity groups intend to address one's privilege, not to foster white guilt. Regardless of the purpose, some affinity group participants 
did not exit the meeting with a positive experience.

Other affinity group attendees found group discussions harmful due to reminders of oppressed nature in society. An African American female stated

To me, it is a way of saying, "HEY CHANEL, YOU ARE BLACK AND YOU ARE OPPRESSED... STILL.... JUST IN CASE YOU FORGOT" I DONT NEED TO BE REMINDED OF HOW OPPRESSED MY PEOPLE ARE. What happened to shining light on the black community. We only see negative things, nothing positive.

From the above response, this affinity group attendee desired more discussion pertaining to the strengths of the racial community. Due to a continuous reminder of one's oppression, the perception of balancing issues fostering strength and struggle in the community were lost. Framing identity as multi-faceted including both positive and negative aspects may have led to a more meaningful affinity group discussion.

\subsection{More Heterogeneity}

Responses within this theme included a desire for more options to connect with other races. For example, a white female stated

I felt that there was never a proper debrief/reconnection after affinity group time. Instead, it felt like we were segregated and then awkwardly thrust back together to discuss something completely unrelated to whatever we had just talked about in our affinity groups. It felt to me like each group had come back from some secret conversation that the other group was not supposed to know about and I always felt extremely disconnected from the people of color after that separation.

The above response viewed affinity groups as a way to segregate racial groups, rather than unify persons. Additionally, a desire to understand other affinity group topics remained a common response among white employees. Many white employees expressed a desire to learn from other races, rather than solely reflecting on self-identity with other white employees. A white male, for instance stated

Their (affinity groups) design separated us from each other rather than creating a space where we could learn from each other. I recognize that the affinity spaces are necessary, but I would have supported another option which allowed people who were comfortable to share and work through issues with a more diverse group.

Similarly, this employee's response shows that a lack of affinity group attendance was due to the homogeneous design where separation was viewed as segregation. Had the organization taken on a heterogeneous approach to affinity group formation, white members may have found the discussions more beneficial.

\subsection{Intersectionality}

While heterogeneous groups were requested by many white employees as a way to learn from others of different races, many employees of racial minorities addressed the need for heterogeneity due to identifying with multiple racial identities. For instance, a female person of color (poc) stated

The 'affinity group' approach was very problematic and slightly traumatic for me. I identify as a mixed person of color. The stark division between poc and white people created a very difficult and hostile situation for me. I chose the poc group because that is my identity. But having to make that choice resulted in hurtful comments and negative reactions to my identity. This would not have happened if the structure of these "affinity" groups had been different. A safe space was announced, but didn't actually exist.

Having to choose a dominant identity remained both hurtful and frustrating to several employees. Employees not identifying as monoracial were required in some cases to choose between an identity characteristic. Such a decision faces difficulty for some employees since identity can involve choices among various racial affiliations. The organizational affinity group structure did not permit heterogeneous affinity groups. Training sites were limited to a certain number of affinity groups to offer due to the number of employees available to facilitate the affinity group meetings, thus the above response reflects the lack of options the non-profit organization was able to provide employees.

\subsection{Exclusion of Identities}

Finally, several employees requested that other identities be present in the affinity groups including income level, gender, Jewish religion, and LGBTQ. Although some of the above requests were available at several training sites, such options were not ubiquitous throughout the organization as a whole. To highlight the exclusion of identity a White male employee stated "I, like many, think that the organization (sic)-required affinity groups should not only be only based on race. Class, gender, and sexual orientation also dictate a classroom environment." From his response, there was clearly a request for other elements of one's identity that were not readily offered nor discussed within the affinity group space. 
RQ2: What will help to enhance diversity within the workplace at large?

\subsection{Organizational Identity}

158 responses addressed one's identity in the non-profit organization in a general sense. Several diversity training sessions were offered throughout the six-week training program that discussed topics related to one's racial and nonracial identity as it pertained to their career. Most diversity sessions tackled racially driven issues as it pertained to K-12 education. Employees were given pre-work prior to entering the training session including reading articles that addressed the racial divide such as excerpts from Beverly Tatum's (2003) Why are all the black kids sitting together in the cafeteria? Of these responses, several sub-themes emerged including legitimizing one's identity, intersectionality, lack of safe-spaces, and surface-level discussion (Table 2).

\subsection{Legitimizing One's Identity}

Many employees mentioned how the organization fostered a productive climate to discuss issues related to one's identity. A Latino Male stated

They (organizational diversity training session leaders) helped me struggle through issues of identity and see how it relates to the classroom. I feel they created a safe space where employees (sic) could feel at home and share personal experiences that led to productive conversations.

From the above response, the organization created a supportive environment for employees to acknowledge their identities while navigating their new career roles. Historically considered a taboo topic, race in the workplace appeared to be an encouraged topic to discuss and thus was supported within organizational diversity sessions. Part of the supportive climate evolved from organizational leaders supporting others to communicate their identity within the workplace. An African American female stated

The diversity sessions were very heartfelt and I appreciate having those sessions. I believe my peers were able to express themselves freely and I was able to gain and understanding of how they felt and how my kids may feel as well if they were in their same shoes such as identity

Not only did leaders of the organization help to legitimize one's own identity, they also encouraged employees to discuss one's identity as a way to relate to their students.

\subsection{Lack of Safe Spaces}

Although many participant responses addressed the utility of an affinity group as a way to openly discuss one's identity, other participants felt the organization did not permit a safe environment. An Asian American male stated of a diversity training session that "I did not feel safe to speak," while a White female stated

The last 2 diversity sessions fostered an uncomfortable environment and tense feelings surrounding race and identity. Employees (sic) felt unsafe sharing their views and the conversations made our school team feel divided because of race rather than united by the same cause.

The above response shows a lack of comfort to express concerns or ideas related to one's identity in the workplace at large. Some employees felt uncomfortable due to a lack of regard for identities other than race, while others like the above employee response were uncomfortable being challenged about racial topics and instead would rather focus on uniting all cultures. The conversations held within the diversity training sessions appeared to cause division for some, rather than an effort to bring multiple identities together to further the progressive efforts of the organization.

\subsection{Intersectionality}

Participants expressed concern about the need to acknowledge intersectionality when discussing identity in the workplace. For example, a white female stated "I understand race is big for the organization (sic), but if we are figuring out our own identities then we need to explore more of that. I think we should focus more on intersectionality." Similarly, some participants went as far as to change the label "identity" to "intersectionality." A person of color stated

Intersectionality competes with the idea of identity, because identity is a fixed thing, so aside from an identification card no person has one single identity. Instead of being used as a buzzword to signify the ambiguous idea of "diversity," intersectionality (sic) actually provides a far more specific way to look at how positionality and identities intersect.

How the organization labeled identity within the diversity session appeared problematic for some employees. The above response signifies the importance of labeling as a way to both legitimize and delegitimize one's identity. If employees believed the term 'identity' to be stagnant and relatively fixed, 'intersectionality' may have served as a more inclusive term.

Other elements of one's identity participants hoped to address was language and low income backgrounds. A white 
female discussed her desire for more discussion regarding language difference stating

Wish that there had been more discussion of different parts of identity in the (sic) training sessions...I think every student's experience with their identity is going to be so different and I think a lot of people didn't engage as much with things other than race... I'm teaching Latino students in the fall and bridging the language gap was something that I wish I had learned more about.

Other employees thought that one's socioeconomic status was an important factor to their identity and relating to others within the workplace. A female Latino American stated

The one thing they do have in common is that they grow up in a low-income community. There are aspects of growing up in a low-income community that affect everyone regardless of their race, and we should have covered that at some point in a $D \& E$ (diversity and equity) session.

From the above participant responses, employees preferred a more complex discussion of one's identity rather than merely one's racial characteristics. Other participants requested that the word "diversity" or "identity" should be replaced with "intersectionality" to describe the training sessions addressing one's identity within the workplace.

\subsection{Surface Level Discussions}

Responses from the final subtheme emerged after many similar sentiments shared regarding the lack of depth in organizational diversity training sessions. Many participants emphasized the need to hold deeper discussions about what led employees to develop certain ideologies. For instance, a female Latino American stated

The sessions barely grazed the surface. I felt like I was in an introductory course as a freshman...these discussions should be held in smaller groups and with people who share the same identity in order to pick up and move on from a common place, and talk about more than the surface points. The facilitation also needs to be much more structured in the questions that are posed.

The above response highlights many sentiments from participants regarding the need for affinity groups to foster more productive conversations about race. The same participant also highlighted the need for homogenous groups to foster more productive conversations. The employee further states

I felt like I had to teach people my experiences and validate articles...I feel they (diversity sessions) were created to placate the white people in the room and get them thinking about race, which in all honesty if they haven't thought or had these conversations before they should not be teaching these kids

As seen in the above participant response, some minorities felt they had to teach white employees rather than learn themselves from well-structured sessions created by facilitators.

\section{Discussion}

The following study provided an important lens into the way individuals communicate identity within the workplace by investigating current employee affinity group perceptions and larger organizational diversity sessions. The ensuing section discusses a salient theme including desire for more intersectionality and heterogeneous group options in the workplace.

Tiger Woods once said I'm more than Black, "I'm Cablinasian," a term he coined for identifying as Caucasian, Black, Indian, and Asian (Fletcher, 1997). Woods identity directly relates to the sentiments shared from the non-profit organization employees regarding affinity group selection. When multiple options existed, affinity group attendees found difficulty selecting one racial group to attend. For instance, one employee, identifying as a Person of Color, reported feelings of difficulty and hostility for having to choose between one elements of identity. Such a decision remains prominent in organizations where employees feel the need to select between two or more identities they apply to label themselves (Rothbard \& Ramajaran, 2009). Rothbard and Ramajaran (2009) claim when experiencing two conflicting identities in the workplace, employees may suppress one identity and thus may experience a negative affect including stress or tension. Individuals reported difficulty during nonracial affinity group selection. For example, a gay or lesbian parent may experience difficulty selecting between a parent and a LGBTQ group. When offering groups simultaneously, employees struggled negotiating which identity to preference.

Several explanations for the non-profit's organizational affinity group design and logistics include organizational resources, facilitator training, and time of day. First, some training sites possessed limited spaces to host affinity groups, whereas others were poorly attended and thus combined with other groups. For example, few employees attended the People of Color (POC) affinity group and were instead directed to the African American affinity group. Such a move may have been problematic for those identifying as POC since organizational employees decided which identity characteristic was more popular, thus directing POC members to shift their identity due to logistical concerns. Organizations looking to incorporate affinity groups should consider the racial and nonracial identity characteristics of 
potential attendees to determine the types of affinity groups desired given the physical setting of the workplace.

Secondly, some employees were dissatisfied with the lack of experience from affinity group facilitators. The only requirement for facilitation was an expressed interest and identification with the racial or nonracial group. Affinity groups operate successfully when structured with leadership positions to ensure stability (McLean-Conner, 2008). Leadership positions require skilled facilitators beginning with meeting goals and outlining specific measures to achieving those goals (McLean-Conner, 2008). As seen, some employees remained frustrated with the lack of experience facilitating sensitive topics such as identity. For example, a white female employee reported a need for "collaboration with a professional dialogue facilitation group" while an African American male stated "Some of the facilitators were not adequate and underprepared to handle some of the in depth conversations." Perhaps hiring professional affinity group facilitators or offering current facilitator's diversity dialogue training would have enhanced one's affinity group experience. A number of existing organizations offer affinity group training such as Seeds For Change, a non-profit organization helping people to organize positive social change, or Organizing For Power, a community organization seeking to combat racism. Each of the organizations offer guided programs for facilitators to learn skills emphasizing participation, democracy, support, and empowerment (Seeds For Change, 2015).

Third, some employees devalued the time of day affinity groups were held. Affinity groups were separated from the regular workday, which may have led to low participation in some groups. Allen (2011) reports that the top 50 organizations for diversity "consider affinity groups to be a crucial aspect to accomplishing business goals, and all of them allow groups to meet during the workday" (p. 89). Organizations looking to incorporate affinity groups should keep the following three guidelines in mind including sufficient meeting spaces and affinity group participants for each identity, quality facilitation, and offering meeting times during the workday, prior to initiating in the workplace.

In addition to logistical concerns, employees from the non-profit organization also desired more discussions about their intersectionality within the homogenous affinity group spaces as well as the diversity sessions at large. Hecht, Warren, Jung, and Krieger (2005) argue that individuals gain membership in a social group which then leads to a social identity, yet individuals maintain memberships in multiple social groups influencing aspects of one's identity. To limit an employee to one social group, the individual must suppress or deny the other identity characteristics. Clair, Beatty, and MacLean (2003) argue "groups that fail to sensitively respond to a person's revelations about a stigmatizing invisible social identity may suffer from decreased cohesion among group members" (p. 29). Invisible identities may include elements of intersectionality, not visible went entering an affinity group space such as identifying as both white and black. If groups fail to articulate differences, group members may become stigmatized or fail to attend subsequent group meetings. Since the organizational diversity sessions primarily focused on racial inequalities, some employees reported suppressing other nonracial identity characteristics, which were seen as an important part of their identity makeup. For example, a female employee identifying as multi-racial stated the following of the larger diversity sessions offered

I still find it so disturbing that we only spoke about racial inequality. It actually makes me feel ill because it seems so obviously wrong to force people to prioritize one of their identities over another, and to create a sort of environment where other types of inequality aren't "relevant."

Some employees went on to specifically address which identities remained suppressed in the larger organizational diversity sessions. A white female identifying as LGBTQ stated

No civil rights or social justice movement can be successful without acknowledging that all oppressed peoples are fighting parallel fights and we, as leaders, must uphold and honor the struggle of all marginalized identity groups (women, members of the LGBTQ community, those seeking political and religious freedom, those from economically disempowered communities, etc.)

The above responses address a need for more communicating intersectionality in both affinity group spaces and larger organizational diversity sessions. Although intersectionality remained a common critique of the non-profit's organizational diversity efforts, many found the affinity group spaces and diversity sessions to be particularly helpful, yet few expanded on why such spaces were helpful. One might presume that affinity groups permitted individuals a space to discuss elements of one's shared identity that were not available in larger organizational discourse. For example, the above response from the LGBTQ member provides an important justification for the LGBTQ affinity group. Since issues pertaining to the community were not actively discussed within the larger organizational setting, perhaps the affinity groups lent a space to do so. Overall, affinity groups were seen as a way to enhance diversity for some, yet the lack of communication about intersectionality and affinity group design remain problematic for many employees.

\section{Limitations}

Although the current study offers important insights into what current employees deem as beneficial diversity initiatives 
in the workplace the researcher was unable to access specific diversity session materials from the non-profit organization. Many employees commented on the lack of intersectionality in diversity sessions, yet the researcher was only able to communicate with two managers from the organization to offer their insights on the specific programs. Each training site had a slightly different diversity session, thus not making all employee experiences the same. To better understand the experiences of employees, future research should address specific diversity training program materials and how those employee experiences may relate or differ.

\section{Theoretical and Practical Implications}

Using IMT to better understand communication within the workplace and affinity group space extends this theoretical framework to a much-needed context. Abrams, O'Connor, and Giles (2002) argue IMT neglects to address identity as constantly changing, claiming current positions of the theory "treat identity as static input-output variable, not something dynamic that is constantly being reconstructed" (p. 229). Affinity group communication provides a dynamic workplace setting, constantly changing depending on the demographics of the workplace and cultural norms. IMT has yet to explore managing intersecting identities in the workplace, which appears a major concern for employees.

As seen in the current research, employees view identity as multi-facted and desire a space to discuss elements of one's changing identity. Additionally, IMT presumes an element of intercultural competence between individuals where implicit privilege remains based on dominant cultural norms (Collier, 1998; Imahori \& Cupach, 2008). For example, a bisexual individual is seen as more privileged than a lesbian or gay male due to the cultural understanding of engaging in a heterosexual relationship. Cultural norms are constantly changing and thus, there are not one set of fixed cultural norms to establish cultural competence across contexts. With more attention being paid to the stigmatization of bisexuals, the cultural norms of the LGBTQ community may be changing and thus how individuals communicate about their identity may also change. Bisexuals may be more willing to discuss their identity if the cultural norm remains supportive. The current study uses IMT to assess a changing context such as workplace affinity groups to view the changing cultural norms. By understanding the changing cultural norms, employees may be able to better manage their identities within the workplace and affinity group spaces.

\section{Conclusion}

Businesses and organizations must understand the potential risks and benefits of both affinity group formation types and the varying levels of privilege when implementing in the workplace. Regardless of the chosen affinity group formation, organizations must hire trained facilitators to ensure that emotional and instrumental goals are met. Failure to do so might result in the above risks posed and thus reluctant employees viewing affinity groups as another organizational diversity fad. Recognizing where companies need to improve begins with how individuals communicate elements of their identity in both the workplace at large and in diversity sessions such as affinity groups. Conversations about identity can no longer include surface level statements such as those on Starbucks coffee cups, rather in-depth discussions uncovering internal and external attributions, elements of intersectionality and a desire to improve workplace communication remains the answer to improving organizational diversity.

\section{References}

4 ways to Regain Control of Your Identity in the Workplace. (2011, July 11). Forbes. Retrieved from: http://www.forbes.com/sites/glennllopis/2011/07/11/4-ways-to-regain-control-of-your-identity-in-the-workplace/

Abrams, J., O'Connor, J., \& Giles, H. (2002). Identity and intergroup communication. In W. B. Gudyknust \& B. Mody (Eds.) Handbook of international and intercultural communication. Thousand Oaks, CA: Sage.

Affinity groups. (2015). Seeds for Change. Retrieved from: http://www.seedsforchange.org.uk/affinitygroups

Ashcraft, K. L., \& Allen, B. (2003). The racial foundation of organizational communication. Communication Theory, 13, 5-38. http://dx.doi.org/10.1093/ct/13.1.5

Attride-Stirling, J. (2001). Thematic networks: An analytic tool for qualitative research. Qualitative Research, 1(3), 385-405. http://dx.doi.org/10.1177/146879410100100307

Biernat, M., Vescio, T. K., \& Billings, L. S. (1999). Black sheep and expectancy violation: integrating two models of social judgment. European Journal of Social Psychology, 29(4), 523-542. http://dx.doi.org/10.1002/(SICI)1099-0992(199906)29:4<523::AID-EJSP944>3.0.CO;2-J

Blitz, L.V., \& Kohl, B. G. (2012). Addressing racism in the organization: The role of White racial affinity groups in creating change. Administration in Social Work, 36(4), 479-498. http://dx.doi.org/10.1080/03643107.2011.624261

Camins, A. (2014, December 10). "The identity and empathy gap," The Huffington Post. Retrieved from: http://www.huffingtonpost.com/arthur-camins/the-identity-and-empathy-_b_6295574.html 
CEO Howard Schultz says other aspects of campaign to continue." Wall Street Journal. Retrieved from: http://www.wsj.com/articles/starbucks-ends-key-phase-in-race-together-campaign-1427076211

Chrobot-Mason, D., Button, S. B., \& DiClementi, J. D. (2001). Sexual identity management strategies: An exploration of antecedents and consequences. Sex Roles, 45(5), 321-336. http://dx.doi.org/10.1023/A:1014357514405

Clair, J. A., Beatty, J. E., \& MacLean, T. L. (2005). Out of sight, but not out of mind: Managing invisible identities in the workplace. Academy of Management Review, 30, 78-118. http://dx.doi.org/10.5465/AMR.2005.15281431

Cole, B. M., \& Salimath, M. S. (2013). Diversity identity management: An organizational perspective. Journal of Business Ethics, 116, 151-161. http://dx.doi.org/10.1007/s10551-012-1466-4

Collier, M. J. (1998). Researching cultural identity. In D. V. Tanno \& A. Gonzailez (Eds.), Communication and identity across cultures (pp. 122-147). Thousand Oaks, CA: Sage.

Croteau, J. M., Anderson, M. Z., \& Vanderwal, B. L. (2008). Models of workplace sexual identity disclosure and management. Group and Organization Management, 33(5), 532-565. http://dx.doi.org/10.1177/1059601108321828

Dean, J. (2015, March 22). "Starbucks ends key phase in 'Race Together' campaign:

Deitch, E. A., Barsky, A., Butz, R. M., Chan, S., Brief, A. P., \& Bradley, J. C. (2003). Subtle yet significant: The existence and impact of everyday racial discrimination in the workplace. Human Relations, 56(11), 1299-1324. http://dx.doi.org/10.1177/00187267035611002

Diversity and affirmative action: Difference. (2015, December 15). Stoney Brook University. Retrieved from: http://www.stonybrook.edu/diversity/aboutus/difference.html

Douglas, P. H. (2008). Affinity groups: Catalyst for inclusive organizations. Employment Relations Today (Wiley), 34(4), 11-18. http://dx.doi.org/10.1002/ert.20171

Employee affinity groups: Definition, purpose, legal issues. (2006, 03). Fair Employment Practices Guidelines, 1-3. Retrieved from http://search.proquest.com/docview/218949953?accountid=35

Fletcher, M. A. (1997, April 23). "Tiger Woods says he's not just Black." The Seattle Times. Retrieved from: http://community.seattletimes.nwsource.com/archive/?date=19970423\&slug=2535313

Goldberg, J. (1990). The psychotherapeutic treatment of cancer patients. New Jersey: Transaction Publishers.

Griffith, K. H., \& Hebl, M. R. (2002). The disclosure dilemma, for gay men and lesbians: "Coming out" at work. Journal of Applied Psychology, 87(6), 1191-1199. http://dx.doi.org/10.1037/0021-9010.87.6.1191

Groggins, A., \& Ryan, A. M. (2013). Embracing uniqueness: The underpinnings of a positive climate for diversity. Journal of Occupational and Organizational Psychology, 86(2), 264-282. http://dx.doi.org/10.1111/joop.12008

Guerin, B. (2005). Combating everyday racial discrimination without assuming racists or racism: New intervention ideas from a contextual analysis. Behavior and Social Issues, 14, 46-70. http://dx.doi.org/10.5210/bsi.v14i1.120

Gulati, M., \& Carbado, D. W. (2000). Working identity. 85, Cornell Law Review 1259-1308.

Hallet, R. E. (2013). Undocumented student success: Navigating constraints related to retention. Journal of Latin American Studies, 5(2), 99-112. http://dx.doi.org/10.18085/llas.5.2.0x00871w50627m17

Harlan, C., \& Contrera J. (2015, March 22). "Starbucks baristas: 'Race together' campaign never found its course.” The Washington Post. Retrieved from:

http://www.washingtonpost.com/business/economy/starbucks-baristas-race-together-campaign-never-found-its-cou rse/2015/03/22/90b2c854-d0d4-11e4-8fce-3941fc548f1c_story.html

Hecht, M. L., Warren, J. R., Jung, E., \& Krieger, J. L. (2005). The communication theory of identity: Development, theoretical perspective, and future directions. In W. B. Gudykunst (Ed.) Theorizing about intercultural communication (pp. 195-215). Thousand Oaks, CA: Sage Publications.

Imahori, T. T., \& Cupach, W. R. (2005). Identity management theory: Facework in intercultural relationships. In W. B. Gudykunst (Ed.) Theorizing about intercultural communication (pp. 195-215). Thousand Oaks, CA: Sage Publications.

Johns Hopkins Affinity Groups and Communities. (2015, December 31). Johns Hopkins University. Retrieved from: http://alumni.jhu.edu/jhaffinities

Kurylo, A. (2013). Challenges and opportunities in inter/cultural communication. In (Ed.) A. Kurylo Inter/cultural communication: Representation and construction of culture (p. 329-348). Thousand Oaks, CA: Sage.

Lambertz, M. (2014). "Diversity, Inclusion, and Fairness": Affinity Group Topic and Satisfaction in a Non-profit 
Organization. Unpublished Manuscript. University of Wisconsin Milwaukee.

Lengnick-Hill, M. (2007). Hidden talent: How leading companies hire, retain, and benefit from people with disabilities. Praeger Publishers: Westport, CT.

Linchevski, L., \& Kutscher, B. (1998). Tell me with whom you're learning, and I'll tell you how Journal for Research in Mathematics Education, 29(5), 533. http://dx.doi.org/10.2307/749732

Marshall, C., \& Rossman, G. (1999). Designing qualitative research ( $3^{\text {rd }}$ edition). London: Sage.

McGlothlen, C. (2006). Be aware of legal limits on an employers discretion in forming and working with employee affinity groups. HR Magazine, 51(7), 706.

McLean-Conner, P. (2008). Support affinity groups to build a positive work environment. Electric Light and Power, 86, 12.

Meenai, Z. (2003). Empowering rural women: An approach to empowering women through credit-base, self-help groups. Laxmi Nagar, Delhi: Aakar Books.

Michael, A., \& Conger, M. C. (2012). Becoming an anti-racist white ally: How a white affinity group can help. Perspectives on Urban Education, 6, 56-60.

Mohammad, S., \& Angell, L.C. (2004). Surface- and deep -level diversity in workgroups: Examining the moderating effects of team orientation and team process on relationship conflict. Journal of Organizational Behavior, 25, 1015-1039. http://dx.doi.org/10.1002/job.293

Noguera, P. A. (2003). The trouble with Black boys: The role and influence of environmental and cultural factors on the academic performance of African American males. Urban Education, 38, 431-459. http://dx.doi.org/10.1177/0042085903038004005

Oetzel, J. G., \& Ting-Toomey, S. (2005). Intercultural perspectives on interpersonal communication. In M. L. Knapp \& J. A. Daly (Eds.) The sage handbook of interpersonal communication (pp. 563-596). Thousand Oaks, CA: Sage.

Parker, P. (2002). Negotiating identity in raced and gendered workplace interactions: The use of strategic communication by African American women senior executives within dominant culture organizations. Communication Quarterly, 50(3), 251-268. http://dx.doi.org/10.1080/01463370209385663

Parsons, J., \& Ridley, K. (2012). Identity, Affinity, Reality: Making the Case for Affinity Groups in Elementary School. Independent School, 71(2), 38-47.

Roberts, E. M. (2011). Creating stronger diversity initiatives in employment settings. Cornell HR Review. Retrieved from: http://www.cornellhrreview.org/creating-stronger-diversity-initiatives-in-employment-settings/

Rothbard, N. P., \& Ramarajan, L. (2009). Checking your identities at the door? Positive relationships between nonwork and work identities. In L. M. Roberts and J. E. Dutton (Eds.), Exploring positive identities and organizations: Building a theoretical and research foundation (pp. 125-144). New York: Routledge Taylor and Francis Group.

Sanchez, D. T., \& Bonam, C. M. (2009). To disclose or not to disclose biracial identity: The effect of biracial disclosure on perceiver evaluations and target responses. Journal of Social Issues, 65(1), 129-149. http://dx.doi.org/10.1111/j.1540-4560.2008.01591.x

Segal, J. A. (2013). Affinity group danger zones. HR Magazine, 58(9), 75-80.

Sheppard, S., \& Kanevsky, L. S. (1999). Nurturing gifted students' metacognitive awareness: Effects of training in homogeneous and heterogeneous classes. Roeper Review, $21(4), \quad 266$. http://dx.doi.org/10.1080/02783199909553974

Shih, M., Young, M. J., \& Bucher, A. (2013). Working to reduce the effects of discrimination: Identity management strategies in organizations. American Psychologist, 68(3), 145-157. http://dx.doi.org/10.1037/a0032250

Singh, P., \& Rampersad, R. (2010). Communication challenges in a multicultural learning environment. Journal of Intercultural Communication, 23, 1404-1634.

Singleton, G. E., \& Linton, C. (2006). Courageous conversations about race: A field guide for achieving equity in schools. Thousand Oaks, CA: Sage.

United States Department of Labor Statistics. (2014, October 13). Retrieved from http://www.dol.gov/oasam/programs/history/herman/reports/futurework/report/chapter1/main.htm

Van Aken, E. M., Monetta, D. J., \& Sink, D. (1994). Affinity Groups: The Missing Link in Employee Involvement. Organizational Dynamics, 22(4), 38-54. http://dx.doi.org/10.1016/0090-2616(94)90077-9 


\section{Appendix A}

Table 1. Affinity Group Perceptions

Themes
Logistics (including those concerned about the time and
location of the affinity group spaces)

Examples

location of the affinity group spaces)

Helpful (where groups served as a space to discuss topics not readily available in workplace dialogue)

"Affinity groups are not set up for SUCCESS! Timing and marketing are not there which makes affinity groups hard to become successful and opportunity to make significant positive change state wide"

"Loved this section and breaking off into affinity groups. It was great to learn about ourselves as well as what our students might identify with"

Harmful (groups reminded employees of one's oppression or white guilt)

"Like many students in this program, I felt that the sessions aimed more at making me feel guilty than at helping me value my identity. I am a white man from an upper-middle class background, but I have signed up to join the organization's effort."

More Heterogeneity (where either white participants sought to learn from blacks or individuals wanted to discuss more than one aspect of their identity)

"Their (affinity groups) design separated us from each other rather than creating a space where we could learn from each other. I recognize that the affinity spaces are necessary, but I would have supported another option which allowed people who were comfortable to share and work through issues with a more diverse group."

Exclusion of Identities (including income level, "I, like many, think that the organization (sic)-required women, Jewish religion, and LGBTQ) affinity groups should not only be only based on race. Class, gender, and sexual orientation also dictate a classroom environment.'

\section{Appendix B}

Table 2. Organizational Identity

\begin{tabular}{|c|c|}
\hline Themes & Examples \\
\hline $\begin{array}{l}\text { Legitimizing Identity (organization fostered a } \\
\text { productive climate to discuss issues related to one's } \\
\text { identity) }\end{array}$ & $\begin{array}{l}\text { "They (organizational diversity training session leaders) } \\
\text { helped me struggle through issues of identity and see } \\
\text { how it relates to the classroom. I feel they created a safe } \\
\text { space where employees (sic) could feel at home and } \\
\text { share personal experiences that led to productive } \\
\text { conversations." }\end{array}$ \\
\hline $\begin{array}{l}\text { Lack of Safe Spaces (organization did not permit a safe } \\
\text { environment) }\end{array}$ & $\begin{array}{l}\text { "The last } 2 \text { diversity sessions fostered an uncomfortable } \\
\text { environment and tense feelings surrounding race and } \\
\text { identity. Employees (sic) felt unsafe sharing their views } \\
\text { and the conversations made our school team feel divided } \\
\text { because of race rather than united by the same cause." }\end{array}$ \\
\hline $\begin{array}{l}\text { Intersectionality (organization needs to acknowledge } \\
\text { multiple identities) }\end{array}$ & $\begin{array}{l}\text { "I understand race is big for the organization (sic), but if } \\
\text { we are figuring out our own identities then we need to } \\
\text { explore more of that. I think we should focus more on } \\
\text { intersectionality." }\end{array}$ \\
\hline $\begin{array}{l}\text { Surface Level Discussions (organizations need to hold } \\
\text { deeper discussions about what led employees to develop } \\
\text { certain ideologies) }\end{array}$ & $\begin{array}{l}\text { "The sessions barely grazed the surface. I felt like I was } \\
\text { in an introductory course as a freshman...these } \\
\text { discussions should be held in smaller groups and with } \\
\text { people who share the same identity in order to pick up } \\
\text { and move on from a common place, and talk about more } \\
\text { than the surface points." }\end{array}$ \\
\hline
\end{tabular}

This work is licensed under a Creative Commons Attribution 3.0 License. 